\title{
Reuse of Industrial Metal Wastes as Partial Replacement of Aggregates in Mortar Production
}

\author{
Nihan GÜLMEZ ${ }^{1 *}$ \\ ${ }^{1}$ Munzur University, Civil Engineering Department, nihangulmez@ munzur.edu.tr, Orcid No: 0000-0002-8650-9670
}

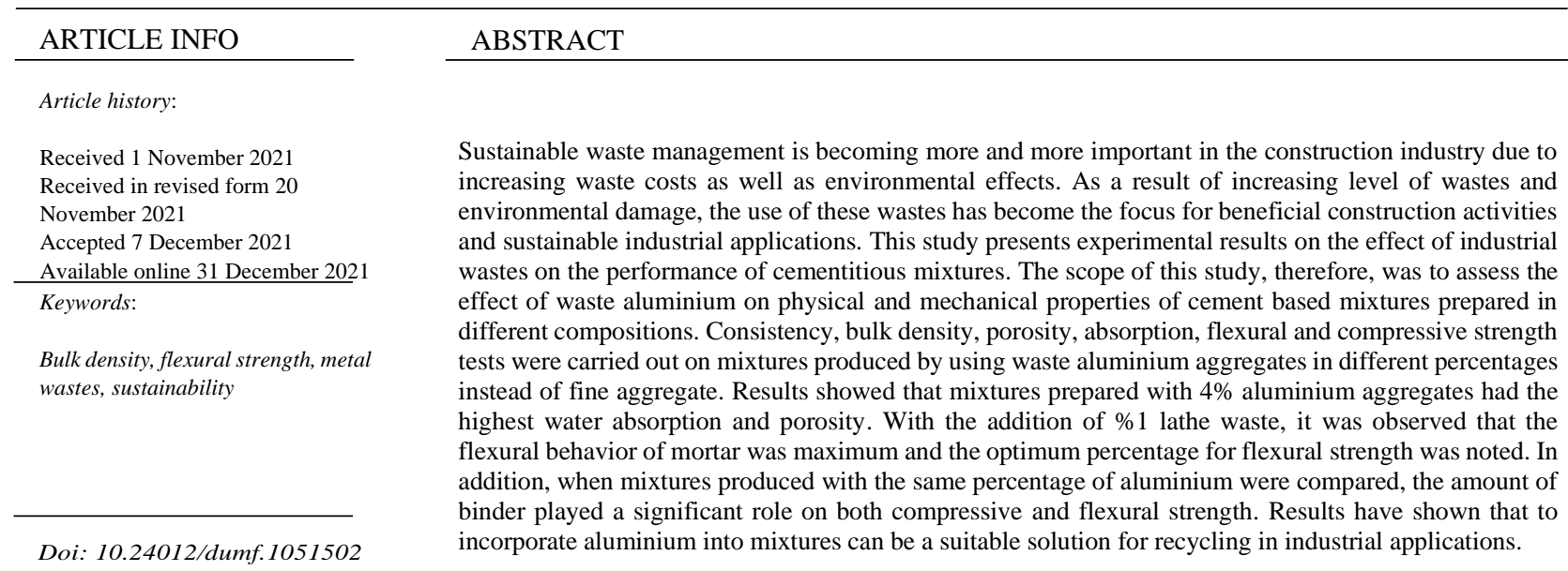

* Corresponding author

\section{Introduction}

In recent years, the standard of living, which has improved considerably with economic development, has led to a sharp increase in industrial wastes that emerged as a big social problem [1]. Over the years, increased amount of waste in the world has created a serious threat to ecology and this situation encourages reuse by recycling of waste in concrete [2].

At this point, sustainable techniques should be created to reuse these wastes [3]. Among these techniques, the use of metal wastes as aggregates in civil engineering applications and in cement based products can be considered as an alternative [4]. Concrete, a composite material, was known for its advantages such as its formability, compressive strength and durability against environmental conditions [5]. The most serious disadvantage of concrete was its very low tensile strength [6]. For this reason, in concrete structures, cracks might develop and those caused a decrease in their strength proceedingly [7]. Manufacturers offered hundreds of fiber types that differ in geometric shape, size, diameter and surface finish [8]. However, due to the environmental damage caused by the production of these fibers, there has been an increasing interest in incorporating recycled waste fibers into concrete recently.
Belferrag et al. [9] investigated effects of waste metal fibers on the durability of concrete due to its economic and environmental advantages. With the addition of waste metal, it was concluded that compressive strength increased by $30.7 \%$ compared to plain concrete [10]. It was explained by Kalpana and Tayu [11] that very high tensile strength was achieved with a $45 \%$ increase in $1 \%$ steel waste compared to plain concrete, and brittle fracture was prevented even in low volume steel wastes. Aluminum chips are one of metal industry wastes [12, 13]. It is important for sustainability to evaluate these wastes as fibers or aggregates in mixtures, even in small volumes [14].

In this study, effects of partial reuse of waste aluminum as aggregate replacement in mortar mixtures were investigated in order to reduce the environmental impact caused by the disposal of waste metals

\section{Material and Method}

CEM I-42.5R Portland Cement was used in the preparation of mixtures and specific gravitiy of cement was found to be 3.11. Three different types of aggregates were used as fine aggregates: aluminum (A1), river sand (A2) and crushed sand (A3). The general view of materials used in the 
mixture was given in Figure 1. Gradation curves of fine aggregates were given in Figure 2.

Fresh mixtures prepared were poured into prism molds having 40x40x160 mm sizes. Fresh mixtures were removed from their molds after 24 hours and left to the curing process at $22^{\circ} \mathrm{C}$ standard temperature. In order to compare engineering properties of mixtures in different compositions, unit weight, consistency, oven-dry and saturated surface-dry bulk densities, apparent porosity, water absorption, compressive and flexural strength of mixtures were calculated by taking average values of three mortars for each mixture.

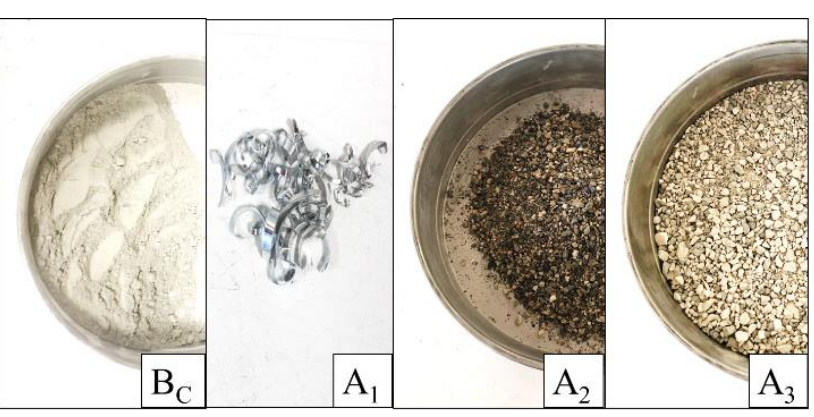

Figure 1. General view of materials used in mixture

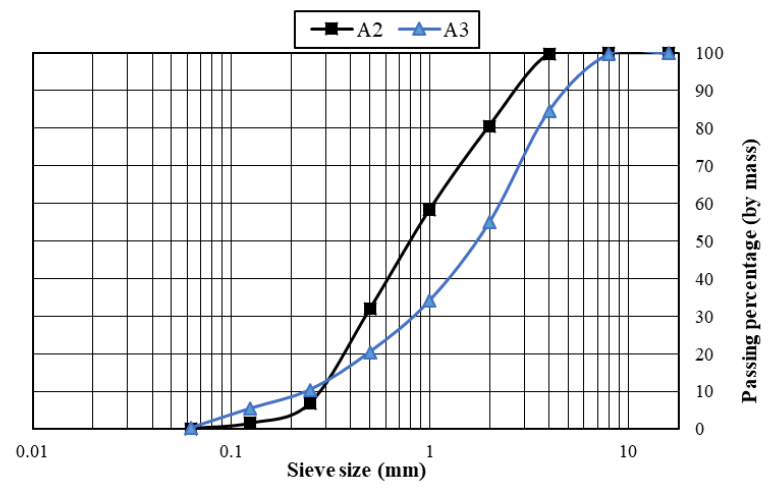

Figure 2. Gradation curve of fine aggregates

Table 1. Constituents ratios of mixtures

\begin{tabular}{cccccc}
\hline Mixtures & $\begin{array}{c}\text { Water } \\
(\mathrm{kg} / \mathrm{m} 3)\end{array}$ & $\begin{array}{c}\text { Cement } \\
(\mathrm{kg} / \mathrm{m} 3)\end{array}$ & \multicolumn{3}{c}{ Aggregates (by volume) } \\
\cline { 4 - 6 } & & & $\begin{array}{c}\mathrm{A} 1 \\
(\%)\end{array}$ & $\begin{array}{c}\mathrm{A} 2 \\
(\%)\end{array}$ & $\begin{array}{c}\mathrm{A} 3 \\
(\%)\end{array}$ \\
\hline $\mathrm{Mx} 1$ & 222 & 467 & 4 & 60 & 36 \\
\hline $\mathrm{Mx} 2$ & 235 & 500 & 4 & 60 & 36 \\
\hline Mx3 & 188 & 400 & 1 & - & 99 \\
\hline
\end{tabular}

\section{Results and Discussion}

\section{Physical properties}

Figures 1 and 2 showed test results for the determination of fresh properties on mixtures. Mx3 mixture containing minimum aluminum percentage showed the highest unit weight value. Unit weight of fresh Mx1 mixture containing $4 \%$ aluminum was calculated as $2236 \mathrm{~kg} / \mathrm{m}^{3}$. Due to the relatively lower specific gravity of aluminum than other aggregates, mixtures containing aluminum showed lower unit weight.
In mixtures with the same water/cement ratio, it could be said that the increased percentage of aluminum increased the workability. Mx2 mixture containing 4\% aluminum had the highest spread diameter of $110.5 \mathrm{~mm}$. Minimum workability value was observed in Mx3 (105 mm) mixture. This situation could be explained by the relatively lower water requirement of aluminum added to mixtures as metal waste aggregate, compared to crushed or river aggregate. As a result, the consistency increased with increasing metal percentage.

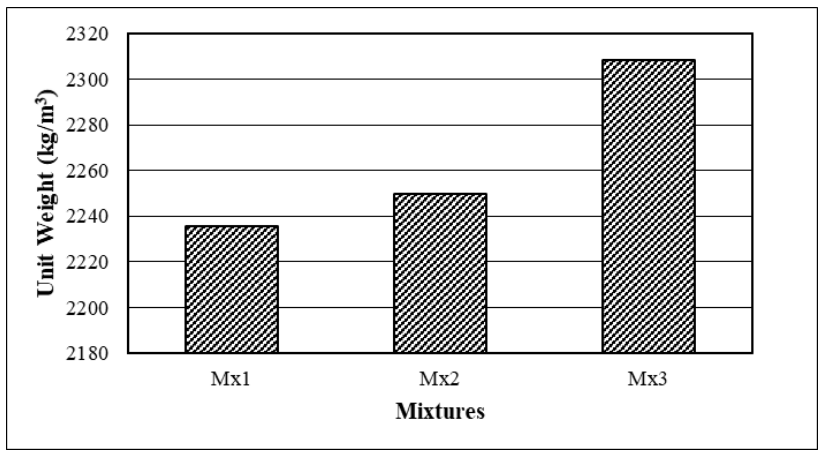

Figure 1. Unit weight values of fresh mixtures

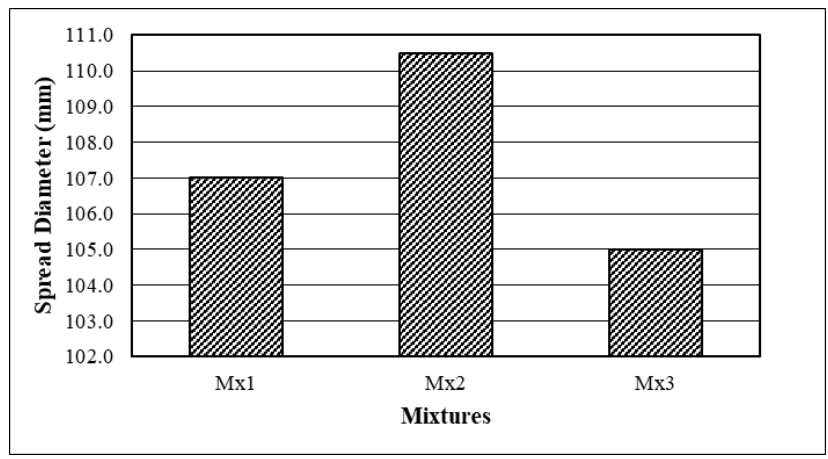

Figure 2. Consistency of fresh mixtures

Figures 3 and 4 show oven-dry and saturated surface dry bulk density values. In all mixtures, Mx3 showed the highest bulk density values, while Mx1 gave the lowest bulk density values. In the study carried out by Tebbal and Rahmouni [15], it was determined that mixture density decreased by approximately $25 \%$ with the addition of $7.5 \%$ aluminum according to the weight of the sand and this was attributed to the reaction of alkali solution and aluminum metal in the paste.

As a result of this study, as the percentage of aluminum in mixtures decreased, values of OD and SSD bulk density increased. This was due to the lower density of aluminum material compared to that of other fine aggregate in this study. In addition, it can be said that there is a decrease in bulk densities due to the high porosity created by aluminum in the form of sawdust in mixture. It was observed by Koçkal et al. [16] that the addition of aluminum particles led to a reduction in strength and bulk density due to entrained air into mixtures.

Figure 5 and Figure 6 showed the porosity and water absorption values of the hardened mixtures. The limited pore connectivity of concrete meant low porosity and low 
water absorption [17]. Water absorption percentage of concrete was expressed as the ratio of the mass of water absorbed by mixture to mass of oven-dried mixture [18]. Aluminum, which are used as substitutes for fine aggregate in this study, can also be considered as hybrid fiber material in different sizes. It was reported that fibers increased total porosity by affecting the air content of mixtures, resulting in lower density and thermal conductivity [19]. Mx3 mixture had the lowest water absorption and apparent porosity values. It was observed by Anike et al. [20] that metal fiber-reinforced recycled aggregate concrete and metal fiber-reinforced blended aggregate concrete had $49 \%$ and $8.8 \%$ higher absorptions, respectively, compared to control concrete. Void content, which explains entrapped macroporosity, was reported to increase with the addition of fibers [21, 22]. This was attributed to defects in the interfacial bond between fibers and the other components of Portland cement concrete resulting from the fiber addition [23]. It was thought that low interfacial adhesion would lead materials to move away from each other and thus increase porosity and decrease density [24]. Mx1 mixture with aluminum percentage of $4 \%$ had the highest water absorption of $10.2 \%$ and apparent porosity of $18.1 \%$. This situation can be explained by the fact that due to geometric properties of aluminum, the higher percentage of use of aluminum in mixtures increases porosity of mixtures. It was concluded that a more compact structure could be created with the use of optimum percentage of aluminum.

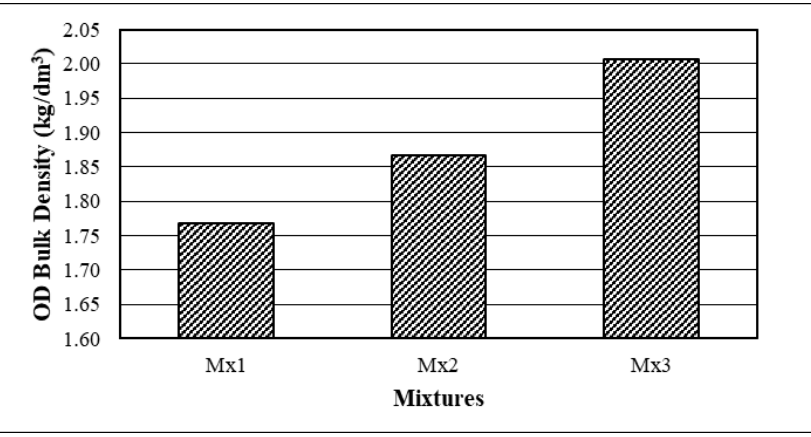

Figure 3. Bulk density (oven-dry) of mixtures

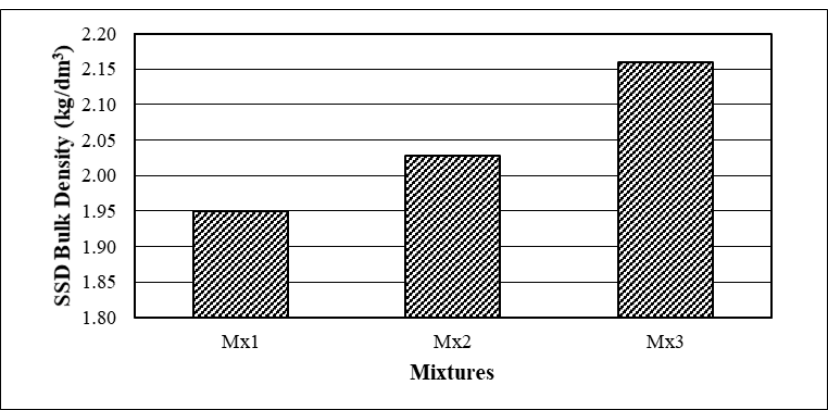

Figure 4. Bulk density (saturated surface-dry) of mixtures

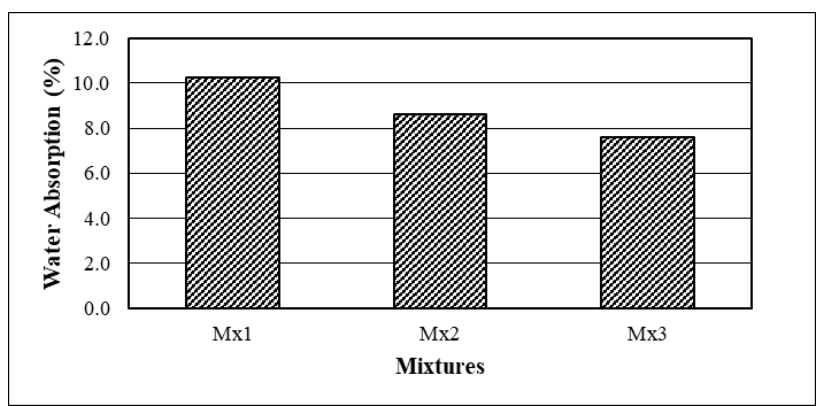

Figure 5. Water absorption of mixtures

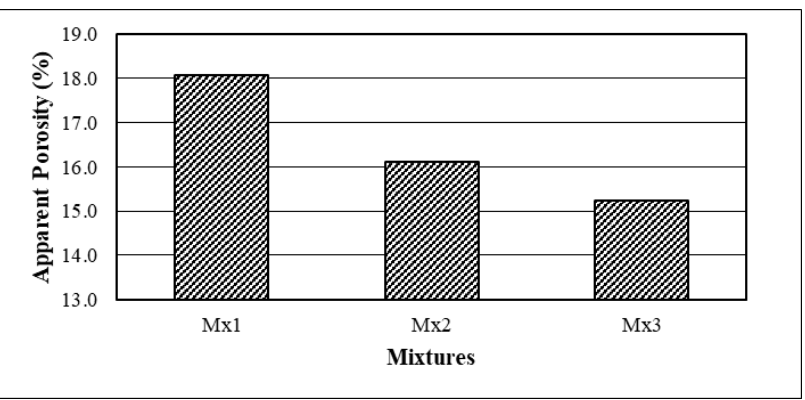

Figure 6. Apparent porosity of mixtures

\section{Mechanical Properties}

Compressive strength results were presented in Figure 7. Mx3 mixture showed the highest compressive strength with 21.9 MPa, while Mx1 mixture (20.9 MPa) gave the lowest compressive strength. It was observed that compressive strength of mixtures to which aluminum was added at different volumetric percentages decreased [25]. In terms of strength and water absorption resistance, the best performance was obtained at two different waste percentages, $1 \%$ and $5 \%$ aluminum, respectively [26]. It was determined that the use of aluminum waste with a maximum size of $4.74 \mathrm{~mm}$ in cement-based mixtures by replacing them with sand sharply reduces compressive strength [27]. According to results, it was concluded that both the amount of binder and types of aggregate play a very important role on mechanical properties of mixtures. It was observed by Poorsaheli et al. [28] that hybrid fibers could increase flexural strength by up to $28 \%$, but had no significant effect on compressive strength. Li et al. [29] reported that micro steel fibers in improving compressive strength of concrete were more effective than long steel fibers. In addition, the higher percentage of shorter fibers in concrete mix, the better workability was achieved [30].

Flexural strength values were given in Figure 8. The reason for the improvement in flexural behavior through the presence of fibers is bridging in crack zone and preventing crack propagation $[31,32]$. Improved properties such as increased load carrying capacity, energy absorption and toughness were due to the increased energy demand for propagation of the crack thanks to the bridging effect of fibers [33, 34]. Today, although various fiber types are produced according to material type, size and shape, costs of these fibers increase the economic burden of construction sector [35]. In addition, other important consequences of fiber production are the rapid destruction of natural resources and increased emissions [36]. As a result, recent 
research aims to increase the use of different types of recycled fiber as an alternative to these commercial fibers. Metal wastes used in this study can be considered as an additive material that undertakes the task of bridging cracks in mixture. Straight and smooth fibers resist pull-out mainly by adhesion, while hooked-end fibers offer additional mechanical strength [37]. Therefore, more energy is required to deform fibers of the second type mentioned [3840]. However, it was reported by Kim et al. [41] that highly curved steel fibers with a curvature above $0.04 \mathrm{~mm}$ negatively affect tensile performance due to poor fiber distribution and excessive matrix damage.

Main advantages of using fiber-like additives are better interlocking mortar matrix and increased flexural strength of mixtures resulting in a non-brittle and ductile fracture [42]. Results of research by Niu [43] showed that mixtures prepared with $0.5 \%$ medium $(13 \mathrm{~mm})$ and $1.5 \%$ long (20 $\mathrm{mm}$ ) fibers gave better flexural behavior compared to other mixtures. The highest flexural strength was shown by Mx3 mixture containing $1 \%$ aluminum. This result contrasts with previous studies that have reported the increasing flexural strength with the increase of fiber content [44]. Therefore, it was concluded that there was an optimum percentage of aluminum to be added to mixtures. Furthermore, when Mx 1 and Mx3 mixtures were compared, it was concluded that Mx3 mixture containing only crushed sand and aluminum aggregates showed better results than Mx1 mixture. In the study by Elinwa and Mbadike [45], it was reported that the optimum replacement value for compressive and flexural strengths was $10 \%$. An increase in strength, as expected, was observed with the decrease of water-cement ratio for all mixtures. However, it is clear that the actual performance of mixtures depends on the cement dosage, the water-cement ratio and the percentage of aluminum as fine aggregate. As a result, based on the obtained strength values, it can be recommended to use both $1 \%$ and $4 \%$ aluminum content for structural and non-structural applications.

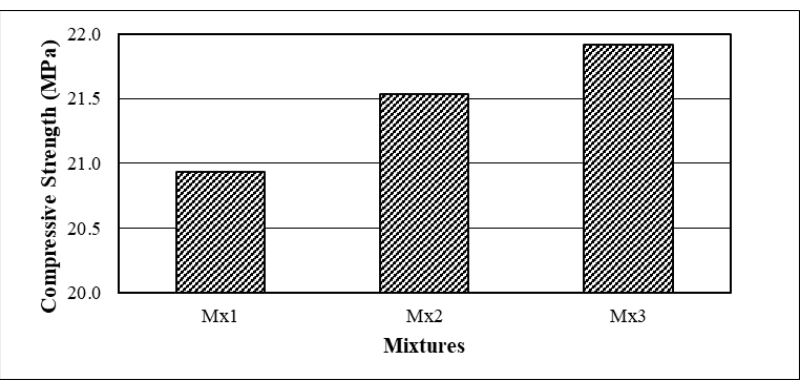

Figure 7. Compressive strength of mixtures

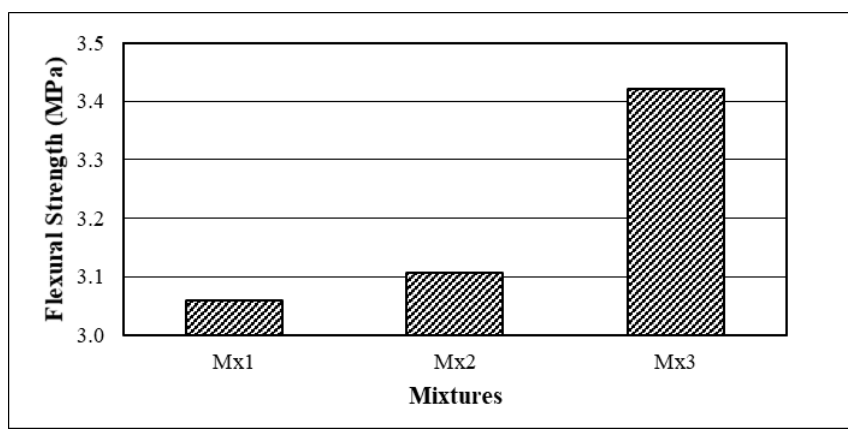

Figure 8. Flexural strength of mixtures

\section{Conclusions}

- Mx1 mixture containing 4\% aluminum showed the lowest compressive strength of 20.9 MPa.

- Mx3 mixture produced by using combination of crushed sand and aluminum as fine aggregate gave the best flexural strength of $3.4 \mathrm{MPa}$.

- Bulk density values increased as the percentage of aluminum in mixtures decreased.

- Mx3 mixture containing 1\% aluminum was found to have the most desirable properties in terms of water absorption and apparent porosity.

\section{References}

[1] M. Batayneh, I. Marie, I. Asi, "Use of selected waste materials in concrete mixes,"Waste Management, vol. 27, pp. 1870-1876, 2007.

[2] A. J. Babafemi, B. Savija, S. C. Paul, V. Anggraini, "Engineering properties of concrete with waste recycled plastic: a review," Sustainability, vol. 10, no 11, pp. 1-26, 2018.

[3] N. K. Sharma, P. Kumar, S. Kumar, B. S. Thomas, R.C. Gupta, "Properties of concrete containing polished granite waste as partial substitution of coarse aggregate," Construction and Building Materials, vol. 151, pp. 158-163, 2017.

[4] J. Junak, N. Stevulova, "Natural aggregate totally replacement by mechanically treated concrete waste," SSP - Journal of Civil Engineering, vol. 10, no 1, pp. 83-90, 2015.

[5] S. Khan, N. Maheshwari, G. Aglave, R. Arora, "Experimental design of green concrete and assessing its suitability as a sustainable building material," Materials Today: Proceedings, vol. 26 pp. 1126-1130, 2020.

[6] F. Min, Z. Yao, T. Jiang, "Experimental and numerical study on tensile strength of concrete under different strain rates," The Scientific World Journal, 2014, Art. no. 173531 .

[7] W. Zeng, Y. Ding, Y. Zhang, F. Dehn, "Effect of steel fiber on the crack permeability evolution and crack surface topography of concrete subjected to freeze- 
thaw damage," Cement and Concrete Research, vol. 138, 2020, Art. no. 106230.

[8] D. Yoo, I. You, "Liquid crystal display glass powder as a filler for enhancing steel fiber pullout resistance in ultra-high-performance concrete," Journal of Building Engineering, vol. 33, 2021, Art. no. 101846.

[9] A. Belferrag, A. Kriker, S. Abboudi, S. Tie Bi, "Effect of granulometric correction of dune sand and pneumatic waste metal fibers on shrinkage of concrete in arid climates," Journal of Cleaner Production, vol. 112, pp. 3048-3056, 2016.

[10] Y. W. Shewalul, "Experimental study of the effect of waste steel scrap as reinforcing material on the mechanical properties of concrete," Case Studies in Construction Materials, vol. 14, 2021, Art. no. e00490.

[11] M. Kalpana, A. Tayu, "Experimental investigation on lightweight concrete added with industrial waste (steel waste)," Materials Today: Proceedings, vol. 22, pp. 887-889, 2020.

[12] M. I. Kadir, M. S. Mustapa, N. A. Latif, A. S. Mahdi, "Microstructural analysis and mechanical properties of direct recycling aluminium chips AA6061/Al powder fabricated by uniaxial cold compaction technique,' Procedia Engineering, vol. 184, pp. 687 - 694, 2017.

[13] N. Gulmez, "Roles of aluminium shavings and calcite on engineering properties of cement-based composites," Journal of Cleaner Production, vol. 277, 2020, Art. no. 124104.

[14] R. Hay, C. P. Ostertag, "On utilization and mechanisms of waste aluminium in mitigating alkalisilica reaction (ASR) in concrete," Journal of Cleaner Production, vol. 212, pp. 864-879, 2019.

[15] N. Tebbal, Z. A. Rahmouni, "Valorization of aluminum waste on the Mechanical Performance of mortar subjected to cycles of freeze-thaw," Procedia Computer Science, vol. 158, pp. 1114-1121, 2019.

[16] N. U. Kockal, O. Beycan, N. Gulmez, "Effect of binder type and content on physical and mechanical properties of geopolymers," Sadhana, 43, 49, 2018.

[17] B. B. Jindal, P. Jangra, A. Garg, "Effects of ultra fine slag as mineral admixture on the compressive strength, water absorption and permeability of rice husk ash based geopolymer concrete," Materials Today: Proceedings, vol. 32, pp. 871-877, 2020.

[18] P. Chakartnarodom, N. Kongkajun, N. Chuankrerkkul, P. Ineure, W. Prakaypan, "Reducing water absorption of fiber-cement composites for exterior applications by crystal modification method," Journal of Metals, Materials and Minerals, vol. 29, pp. 90-98, 2019.

[19] B. Nagy, S. Nehme, D. Szagri, "Thermal properties and modeling of fiber reinforced concretes," Energy Procedia, vol. 78, pp. 2742-2747, 2015.
[20] E.E. Anike, M. Saidani, A. Olubanwo, M. Tyrer, E. Ganjian, "Effect of mix design methods on the mechanical properties of steel fibre-reinforced concrete prepared with recycled aggregates from precast waste," Structures, vol. 27, pp. 664-672, 2020.

[21] A.M. Zeyad, A. Khan, B. Tayeh, "Durability and strength characteristics of high-strength concrete incorporated with volcanic pumice powder and polypropylene fibers," Journal of Materials Research and Technology, vol. 9, pp. 806-818, 2020.

[22] B.C. Oni, J. Xia, M. Liu, "Mechanical properties of pressure moulded fibre reinforced pervious concrete pavement brick," Case Studies in Construction Materials, vol. 13, 2020.

[23] S. Abdallah, M. Fan, D.W. Rees, "Bonding mechanisms and strength of steel fiber-reinforced cementitious composites: Overview," Journal of Materials in Civil Engineering, vol. 30, 2018, Art. no. 04018001.

[24] T. Alomayri, F. Shaikh, I.M. Low, "Characterisation of cotton fibre-reinforced geopolymer composites," Composites Part B-Engineering, vol. 50, pp. 1-6, 2013.

[25] O. M. Ofuyatan, A. A. Ivoke, A. M. Olowofoyeku, A. Adesina, and J. Oluwafemi, "Effect of waste aluminium shavings on the bond characteristics of laterized concrete," Advances in Materials Research, vol. 8, no. 1, pp. 25-36, Mar. 2019.

[26] N. L. Rahim, N. M. Ibrahim, S. Salehuddin, R. C. Amat, S. A. Mohammed, C. R. Hibadullah, "The Utilization of Aluminum Waste as Sand Replacement in Concrete," Key Engineering Materials, vol. 594595, pp. 455-459, Dec. 2013.

[27] A. S. Aadi, T. K. M. Ali, R. A. A. Ali, M. M. Salman, "The mechanical properties of green mortar contained aluminum wastes as substitution of sand," Materials Today: Proceedings, vol. 42, pp. 3002-3009, 2021.

[28] H.B. Poorsaheli, A. Behravan, S.T. Aghda, "Durability performance of hybrid reinforced concretes (steel fiber + polyolefin fiber) in a harsh marine tidal zone of Persian Gulf," Construction and Building Materials, vol. 266, 121176, 2021.

[29] J. Li, E. Zhao, J. Niu, C. Wan, "Study on mixture design method and mechanical properties of steel fiber reinforced self-compacting lightweight aggregate concrete," Construction and Building Materials, 2020, Art. no. 121019.

[30] Y. Mohammadi, S. Singh, S. Kaushik, "Properties of steel fibrous concrete containing mixed fibres in fresh and hardened state," Construction and Building Materials, 22, pp. 956-965, 2008.

[31] G.B. Golpasand, M. Farzam, S.S. Shishvan, "Behavior of recycled steel fiber reinforced concrete under uniaxial cyclic compression and biaxial tests," Construction and Building Materials, vol. 263, 2020, Art. no. 120664 
[32] I. Rahmani, A. Maleki, M.A. Lotfollahi-Yaghin, “A laboratory study on the flexural and shear behavior of $\mathrm{RC}$ beams retrofitted with steel fiber-reinforced selfcompacting concrete jacket," Iranian Journal of Science and Technology-Transactions of Civil Engineering, pp. 1-17, 2020.

[33] H.A. Alkufi, M. Al-Sherrawi, "Efficiency of steel fiber on carrying capacity of short square columns," Civil Engineering Journal, vol. 4, pp. 1584-1594, 2018.

[34] N. Buratti, C. Mazzotti, M. Savoia, "Post-cracking behaviour of steel and macro-synthetic fibre-reinforced concretes," Construction and Building Materials, vol. 25, pp. 2713-2722, 2011.

[35] B. Ali, L. A. Qureshi, S. U. Khan, "Flexural behavior of glass fiber-reinforced recycled aggregate concrete and its impact on the cost and carbon footprint of concrete pavement," Construction and Building Materials, vol. 262, 2020, Art. no. 120820.

[36] A. S. Moghadam, F. Omidinasab, M. Abdalikia, "The effect of initial strength of concrete wastes on the fresh and hardened properties of recycled concrete reinforced with recycled steel fibers," Construction and Building Materials, vol. 300, 2021, Art. no. 124284.

[37] T. Simoes, C. Octavio, J. Valença, H. Costa, D. Diasda-Costa, E. Julio, "Influence of concrete strength and steel fibre geometry on the fibre/matrix interface," Composites Part B, vol. 122, pp. 156-164, 2017.

[38] S. Abdallah, M. Fan, K. Cashell, "Pull-out behaviour of straight and hooked-end steel fibres under elevated temperatures," Cement and Concrete Research, vol. 95, pp. 132-140, 2017.

[39] Z. Wu, C. Shi, W. He, L. Wu, "Effects of steel fiber content and shape on mechanical properties of ultra high performance concrete," Construction and Building Materials, vol. 103, pp. 8-14, 2016.
[40] J. Feng, W. Sun, X. Wang, X. Shi, "Mechanical analyses of hooked fiber pullout performance in ultrahigh-performance concrete," Construction and Building Materials, vol. 69, pp. 403-410, 2014.

[41] J. Kim, Y.S. Jang, D. Yoo, "Enhancing the tensile performance of ultra-high-performance concrete through novel curvilinear steel fibers," Journal of Materials Research and Technology, vol. 9, pp. 75707582, 2020.

[42] A. Moron, D. Ferrandez, P. Saiz, M. Alvarez, C. Moron, "New system for vibrating and orientation of steel fibers in masonry mortars," Journal of Building Engineering, vol. 43, 2021, Art. no. 102827.

[43] Y. Niu, J. Wei, C. Jiao, "Crack propagation behavior of ultra-high-performance concrete (UHPC) reinforced with hybrid steel fibers under flexural loading," Construction and Building Materials, vol. 294, 2021, Art. no. 123510.

[44] I. Yang, C. Joh, K. Kim, “A comparative experimental study on the flexural behavior of high-strength fiberreinforced concrete and high-strength concrete beams," Advances in Materials Science and Engineering, pp. 113,2018 .

[45] A. U. Elinwa, E. Mbadike, "The Use of Aluminum Waste for Concrete Production," Journal of Asian Architecture and Building Engineering, vol. 10, no. 1, pp. 217-220, 2011. 